\title{
GENDER-ASSOCIATED DIFFERENCES IN THE PREVALENCE OF CENTRAL OBESITY USING WAIST CIRCUMFERENCE AND WAIST-TO-HEIGHT RATIO, AND THAT OF GENERAL OBESITY, IN SLOVAK ADULTS
}

\author{
Melinda Csongová1, Katarína Volkovová2, Martin Gajdoš³, Radana Gurecká1, Ivana Koborová1, Aurélia Líšková4, \\ Katarína Šebeková 1 \\ ${ }^{1}$ Institute of Molecular Biomedicine, Faculty of Medicine, Comenius University in Bratislava, Bratislava, Slovak Republic \\ ${ }^{2}$ Institute of Biology, Medical Faculty, Slovak Medical University, Bratislava, Slovak Republic \\ ${ }^{3}$ Department of Clinical and Experimental Pharmacotherapy, Medical Faculty, Slovak Medical University, Bratislava, Slovak Republic \\ ${ }^{4}$ Department of Immunology and Immunotoxicology, Medical Faculty, Slovak Medical University, Bratislava, Slovak Republic
}

\section{SUMMARY}

Objectives: Central obesity represents an increased risk to develop cardiovascular diseases. Guidelines of international societies suggest estimating central obesity by measuring waist circumference (WC). Robust statistical data in literature provide evidence on the superiority of waist-to-height ratio (WHtR) over WC and body mass index (BMI) for detecting cardiometabolic risk in both genders. Based on measurements of weight, height and waist circumference we compared the prevalence of central obesity using both the above mentioned criteria in the apparently healthy Slovak adults, and compared the prevalence of central obesity to that of general obesity (BMI).

Methods: Data collected from 5,184 individuals ( $45 \%$ males) aged $\geq 18$ years in four cross-sectional studies carried out between the years 2009-2012 were subjected to secondary analysis.

Results: Waist circumference underestimated central obesity in males and overestimated in females: $37.3 \%$ of males and $41.8 \%$ of females presented central obesity according to WC, $54.2 \%$ males and $34.9 \%$ females according to WHtR. $17.3 \%$ of males centrally obese according to WC present WHtR $<0.5$; while $7.8 \%$ of females centrally obese according to their WHtR do not display increased WC. The frequency of central obesity increased with age. According to BMl, the prevalence of overweight was $39 \%$ in males and $22 \%$ in females; that of obesity was $17 \%$ and $15 \%$, respectively.

Conclusion: The prevalence of central obesity estimated using WC vs. WHtR differs significantly in Slovak adults. WHtR is considered superior for detection of the risk of future development of cardiovascular afflictions. Thus, further studies addressing the gender-associated discordance of central obesity measures are required to determine whether our results are consistent across geographical regions and ethnic groups.

Key words: central obesity, waist circumference, waist-to-height ratio, BMl, gender

Address for correspondence: M. Csongová, Institute of Molecular Biomedicine, Faculty of Medicine, Comenius University in Bratislava, Sasinkova 4, 81108 Bratislava, Slovak Republic. E-mail: melinda.csongova@gmail.com

https://doi.org/10.21101/cejph.a4719

\section{INTRODUCTION}

Obesity, an excessive accumulation of body fat and increased body weight, is associated with negative health effects and reduced life expectancy. Rather than increased body weight per se, accumulation of visceral fat is associated with high blood pressure, atherogenic dyslipidemia, insulin resistance, type 2 diabetes, cardiovascular diseases, and certain cancers (1-3).

To identify people at increased health risk in general practice and epidemiological studies, visceral obesity is approximated by estimation of central obesity (CO). Guidelines of international societies suggest estimating $\mathrm{CO}$ by measuring of waist circumference (WC) employing gender- and ethnicity-specific cut-points
$(4,5)$. The WC may over- and under-estimate $\mathrm{CO}$ in tall and short individuals with similar WC, respectively. Thus, the waist-toheight ratio $(\mathrm{WHtR}) \geq 0.5$ has been proposed as a proxy for $\mathrm{CO}$ $(6,7)$. Systemic reviews and meta-analyses of studies involving several ethnic groups provide robust statistical evidence on the superiority of WHtR over WC and body mass index (BMI) for detecting cardiometabolic risk factors in both genders (2,3). Individuals supposed to be at risk of manifestation of cardiometabolic risk factors by their WC or WHtR are missed by BMI screening $(8,9)$. However, concordance or discrepancy in evaluation of CO using WC vs. WHtR is seldom tackled.

Information on the prevalence of overweight and obesity in Slovak adults comes from anthropometric measurements con- 
ducted in the years 2003 to $2005(10,11)$, and from self-reported data on weight and height collected in 2009 (12). Neither of these studies employed WHtR as a measure of adiposity.

To this point we analyzed the association of estimates of $\mathrm{CO}$ evaluated according to $\mathrm{WC}$ and $\mathrm{WHtR}$, and their relationship to BMI, in pooled data from 4 cross-sectional studies comprising 5,184 individuals aged $\geq 18$ years $(13-16)$. We hypothesized that WC and WHtR match the best in individuals with average height, and that a mismatch increases evenly with increments or decrements of the standard deviation of heights.

\section{MATERIALS AND METHODS}

This is a secondary analysis of data obtained in 4 cross-sectional studies conducted during the years 2007-2012 on apparently healthy volunteers or general population. Studies were performed in accordance with the principles of the Declaration of Helsinki. Study protocols were approved by the Ethics Committee of the Slovak Medical University (13-15), or that of Bratislava Selfgoverning Region (16). All subjects signed an informed consent to participate.

\section{Study Population}

Caucasians of Middle-European descent aged 18 to 83 years (mean age: $33.1 \pm 12.1$ years in males and $33.9 \pm 11.6$ years in females) residing, working or studying in Bratislava and surroundings were recruited in 3 studies (14-16), and those from 7 Slovak cities in another study (13). Recruitment was performed via general practitioners, using advertisements posted in frequented public locations, or via provided information on the possibility to participate at companies and secondary schools. In all studies exclusion criteria were any acute or serious chronic illnesses, unstable physical condition, and in women pregnancy and lactation.

\section{Procedures}

In all studies anthropometric measurements were performed by trained medical staff. Electronic scales (Omron BF510, Kyoto, Japan), extendable stadiometers (wall-mounted Harpenden stadiometer, Holtain Ltd., Crymych, UK; or portable stadiometers model 214 Rod, Seca Corp., Hamburg, Germany), and flexible inelastic belt-type tapes were used to determine body weight, height, and $\mathrm{WC}$, respectively.

Data on age, gender, body weight, height, and WC of individuals aged $\geq 18$ years were extracted from pertinent databases. After exclusion of the subjects with incomplete data $(n=54)$, 5,184 individuals $(45.3 \%$ males $)$ were included into analyses. $\mathrm{BMI}$ and WHtR were calculated. CO was classified as $\mathrm{WC} \geq 94$ $\mathrm{cm}$ in males and $\geq 80 \mathrm{~cm}$ in females (17); and as WHtR $\geq 0.5$ (8). Subjects were categorized into 4 groups: 1) lean subjects: $\mathrm{WC}<$ cut-point and WHtR $<0.5$ (Lean, WC-WHtR-); centrally obese by 2 ) both indicators ( $\mathrm{WC}+\mathrm{WHtR}+$ ), or according to a single indicator: 3) WC+WHtR-, and 4) WC-WHtR+. Heights in which both methods showed $100 \%$ agreement were identified. To reveal trends in the differences of the two proxies, individuals shorter or taller than the height interval in which the two indicators matched were sorted into groups by $5 \mathrm{~cm}$ of height, except for the shortest and the tallest subjects. E.g., in males, merged marginal groups of height (e.g. $\leq 167 \mathrm{~cm}$ and $\geq 195 \mathrm{~cm}$ ) were created since there were only 14 males shorter than $162 \mathrm{~cm}$, and only 6 with height of $\geq 199 \mathrm{~cm}$. Similar reasons led us to group the shortest and the tallest females. Additionally, the subjects were categorized ac-

Table 1. Cohort characteristics

\begin{tabular}{|c|c|c|c|c|c|c|c|}
\hline & $\mathrm{n}$ & Age (years) & Height (cm) & Weight (kg) & WC (cm) & WHtR & $\begin{array}{l}\text { Body mass index } \\
\left(\mathrm{kg} / \mathrm{m}^{2}\right)\end{array}$ \\
\hline Males & 2,349 & $\begin{array}{c}33.1 \pm 12.1 \\
(18-83)\end{array}$ & $\begin{array}{l}178.8 \pm 6.9 \\
(140-204)\end{array}$ & $\begin{array}{c}83.4 \pm 15.5 \\
(48-163)\end{array}$ & $\begin{array}{c}90.8 \pm 13.0 \\
(60-150)\end{array}$ & $\begin{array}{l}0.51 \pm 0.07 \\
(0.33-0.83)\end{array}$ & $\begin{array}{c}26.1 \pm 4.5 \\
(16.0-53.2)\end{array}$ \\
\hline Females & 2,835 & $\begin{array}{c}33.9 \pm 11.6 \\
(18-83)\end{array}$ & $\begin{array}{l}165.5 \pm 6.3 \\
(143-189)\end{array}$ & $\begin{array}{c}67.3 \pm 15.5 \\
(40-170)\end{array}$ & $\begin{array}{c}79.9 \pm 13.3 \\
(53-148)\end{array}$ & $\begin{array}{l}0.48 \pm 0.08 \\
(0.39-0.95)\end{array}$ & $\begin{array}{c}24.5 \pm 5.4 \\
(15.2-58.8)\end{array}$ \\
\hline
\end{tabular}

WC - waist circumference, WHtR - waist-to-height ratio, BMI - body mass index; data are given as mean \pm SD and range (in brackets)

Table 2. Prevalence of body mass categories and central obesity

\begin{tabular}{|c|c|c|c|}
\hline & Males & Females & p-value \\
\hline Underweight $\left(\mathrm{BMI}<18.5 \mathrm{~kg} / \mathrm{m}^{2}\right)$ & $47(2.0 \%)$ & $155(5.5 \%)$ & $<0.001$ \\
\hline Normal weight (BMl: $18.5-24.9 \mathrm{~kg} / \mathrm{m}^{2}$ ) & $977(41.6 \%)$ & $1,657(58.4 \%)$ & $<0.001$ \\
\hline Overweight (BMI: $25.0-29.9 \mathrm{~kg} / \mathrm{m}^{2}$ ) & $926(39.4 \%)$ & $613(21.6 \%)$ & $<0.001$ \\
\hline \multicolumn{4}{|l|}{ Obesity } \\
\hline Stage I (BMl: $30.0-34.9$ kg/m²) & $301(12.8 \%)$ & $265(9.3 \%)$ & $<0.001$ \\
\hline Stage II (BMl: $35.0-39.9$ kg/m²) & $76(3.2 \%)$ & $94(3.3 \%)$ & 0.872 \\
\hline Stage III $\left(\mathrm{BMI}>40.0 \mathrm{~kg} / \mathrm{m}^{2}\right)$ & $22(0.9 \%)$ & $51(1.8 \%)$ & 0.009 \\
\hline \multicolumn{4}{|l|}{ Central obesity } \\
\hline WC ( $\geq 94 \mathrm{~cm}$ males; $\geq 80 \mathrm{~cm}$ females) & $875(37.2 \%)$ & $1,185(41.8 \%)$ & $<0.001$ \\
\hline WHtR $(\geq 0.5)$ & $1,272(54.2 \%)$ & $991(35.0 \%)$ & $<0.001$ \\
\hline
\end{tabular}

$\mathrm{BMI}$ - body mass index, $\mathrm{WC}$ - waist circumference, $\mathrm{WHtR}$ - waist-to-height ratio, data are given as number of subjects and percentage 
cording to BMI as those presenting underweight (BMI $<18.5 \mathrm{~kg} /$ $\mathrm{m}^{2}$ ), normal weight (BMI: $18.5-24.9 \mathrm{~kg} / \mathrm{m}^{2}$ ), overweight (BMI: 25.0-29.9 kg/m²), class I (BMI: $30.0-34.9 \mathrm{~kg} / \mathrm{m}^{2}$ ), class II (BMI: $\left.35.0-39.9 \mathrm{~kg} / \mathrm{m}^{2}\right)$, and class III (BMI $\left.>40.0 \mathrm{~kg} / \mathrm{m}^{2}\right)$ obesity.

\section{Statistical Analysis}

In males and females, the prevalence of $\mathrm{CO}$ according to $\mathrm{WC}$ or WHtR was calculated with regard to height, BMI category, or decades of age. Data are given as mean \pm standard deviation, or as percentages. Categorical data were compared by chi-square test or McNemar's test (exact, 2-tailed), as appropriate. $\mathrm{P}<0.05$ was considered significant. Statistical analyses were performed using SPSS version 22 software (SPSS Inc., Chicago, IL, USA).

\section{RESULTS}

Cohort characteristics are given in Table 1. The prevalence of underweight, normal BMI, overweight, and obesity and that of $\mathrm{CO}$ according to $\mathrm{WC}$ and WHtR cut-points are summarized in Table 2.

\section{Males}

Central obesity: The prevalence of CO employing WC cutpoint was significantly lower (37.2\%) if compared with that evaluated according to WHtR $(54.2 \%$, McNemar p < 0.001) (Table 2). WHtR correlated significantly with WC $\left(\mathrm{y}=0.005 \mathrm{x}+0.015, \mathrm{R}^{2}=\right.$ $0.927, \mathrm{p}<0.001)$. WC and WHtR classified concordantly central obesity or leanness in $82.3 \%(n=1,934)$ of males; a mismatch between 2 proxies of $\mathrm{CO}$ was observed in 415 (17.7\%) subjects (Table 3).

Both methods fully matched in classification of CO in 188 $\mathrm{cm}$ and $189 \mathrm{~cm}$ high males (Figure 1a). 17.3\% of males were classified as CO by WHtR but not according to WC (Table 3). Since all of them were shorter than $188 \mathrm{~cm}$ (Fig. 1a), thus WC vs. WHtR underestimated CO in $19.2 \%$ of shorter subjects. Among all participants, $0.4 \%$ presenting $\mathrm{WC} \geq 94 \mathrm{~cm}$ displayed WHtR $<0.5$ (Table 3). All of them were taller than $189 \mathrm{~cm}$ (Fig. 1a), thus among tall men mismatch reached $6.0 \%$.

McNemar's test indicated significant difference between classifications in all height categories bellow $188 \mathrm{~cm}(\mathrm{p}<0.001$, all), and in males $190-194 \mathrm{~cm}$ tall $(\mathrm{p}=0.016)$. In comparison with WHtR, WC underestimated CO in all age-decade groups (Figure
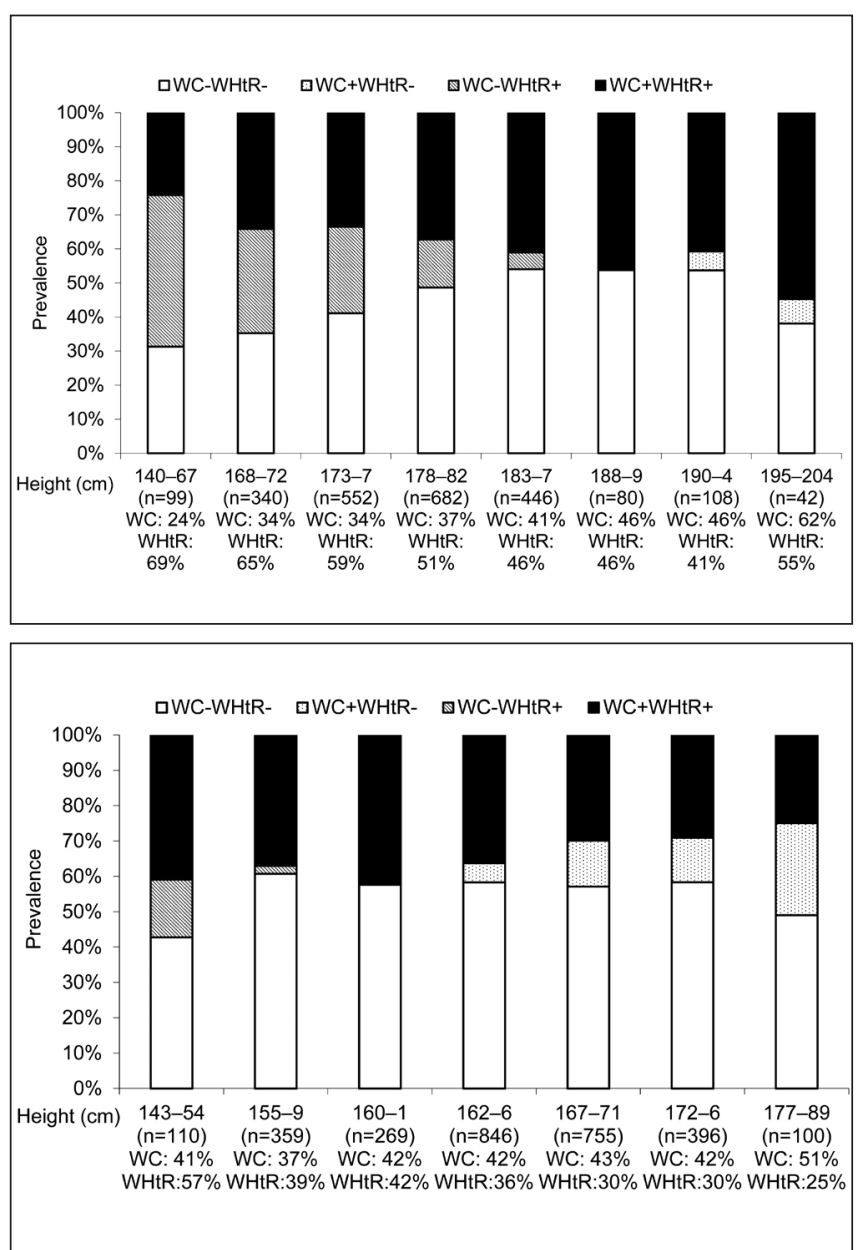

Fig. 1. Prevalence of central obesity estimated by waist circumference and waist-to-height ratio in relation to height in males (1a) and females (1b).

Central obesity was classified as WC $\geq 94 \mathrm{~cm}$ in males and $\geq 80 \mathrm{~cm}$ in females (17) and as $\mathrm{WHtR} \geq 0.5$ (8). Subjects were grouped by $5 \mathrm{~cm}$ increments/decrements from the height in which WC and WHtR matched in classification of central obesity. Four categories were used to characterize the prevalence of central obesity: WCWHtR-: lean subjects: $W C<94 \mathrm{~cm}$ (males) or $<80 \mathrm{~cm}$ in females and WHtR $<0.5$ WC+WHtR-: centrally obese only according to WC; WC-WHtR+: centrally obese only according to $\mathrm{WHtR} ; \mathrm{WC}+\mathrm{WH} \mathrm{tR}+$ : centrally obese according to both measures. Height intervals are indicated in the first row under the bars. Number of probands (n) in each height category is given in the second row. WC - prevalence of central obesity classified according to waist circumference cut-point; WHtR - prevalence of central obesity classified according to waist-to-height ratio.

2). The lowest discordance (3.6\%) was observed in 60-69 years old subjects, the highest $(24.3 \%)$ in those aged $40-49$ years.

Table 3. Prevalence of central obesity according to waist circumference or waist-to-height ratio in underweight/lean (BMI $\leq 24.9$ $\left.\mathrm{kg} / \mathrm{m}^{2}\right)$ and overweight/obese $\left(B M I \geq 25.0 \mathrm{~kg} / \mathrm{m}^{2}\right)$ males and females

\begin{tabular}{|l|c|c|c|c|c|c|c|c|}
\hline \multirow{2}{*}{} & \multicolumn{4}{|c|}{ Males } & \multicolumn{4}{c|}{ Females } \\
\cline { 2 - 10 } & \multicolumn{2}{|c}{ WC } & \multicolumn{2}{c|}{ WHtR } & \multicolumn{2}{c|}{ WC } & \multicolumn{2}{c|}{ WHtR } \\
\cline { 2 - 10 } & $<94 \mathrm{~cm}$ & $\geq 94 \mathrm{~cm}$ & $<0.5$ & $\geq 0.5$ & $<80 \mathrm{~cm}$ & $\geq 80 \mathrm{~cm}$ & $<0.5$ & $\geq 0.5$ \\
\hline $\mathrm{BMI} \leq 24.9 \mathrm{~kg} / \mathrm{m}^{2}$ & $974(41.5 \%)$ & $50(2.1 \%)$ & $869(36.9 \%)$ & $155(6.6 \%)$ & $1,522(53.7 \%)$ & $290(10.2 \%)$ & $1,650(58.2 \%)$ & $162(5.7 \%)$ \\
\hline $\mathrm{BMI} \geq 25.0 \mathrm{~kg} / \mathrm{m}^{2}$ & $500(21.3 \%)$ & $825(35.1 \%)$ & $208(8.9 \%)$ & $1,117(47.6 \%)$ & $128(4.5 \%)$ & $895(31.6 \%)$ & $194(6.8 \%)$ & $829(29.3 \%)$ \\
\hline WHtR $<0.5$ & $1,068(45.4 \%)$ & $9(0.4 \%)$ & - & - & $1,624(57.3 \%)$ & $220(7.8 \%)$ & - & - \\
\hline WHtR $\geq 0.5$ & $406(17.3 \%)$ & $866(36.9 \%)$ & - & - & $26(0.9 \%)$ & $965(34.0 \%)$ & - & - \\
\hline
\end{tabular}

$\mathrm{BMI}$ - body mass index, WC - waist circumference, WHtR - waist-to-height ratio; data are given as number of subjects and percentage, percentage given in bold indicate the discordance between 2 methods compared 


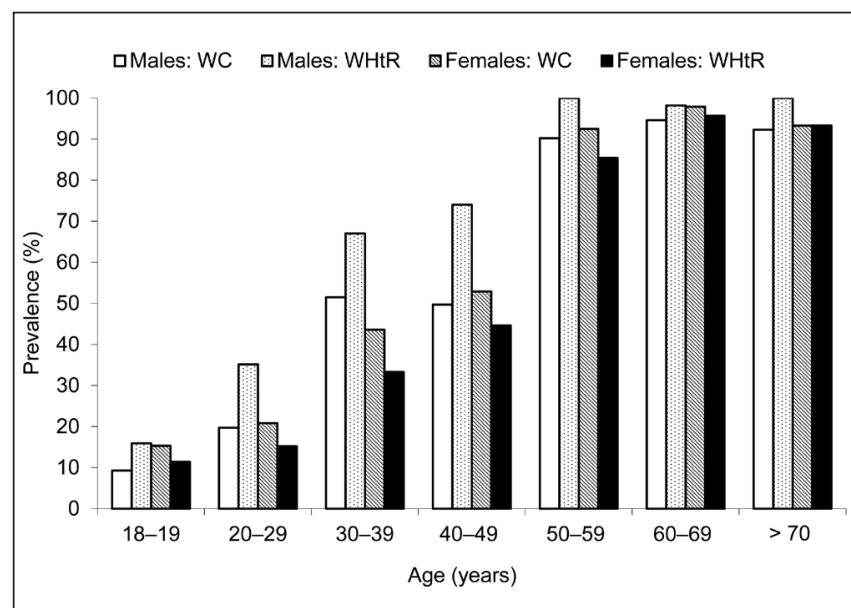

Fig. 2. Age-dependent prevalence of central obesity classified according to waist circumference (WC) and waist-to-height ratio (WHtR) in males and females.

Body mass index: Regardless of the method of CO estimation, none of the males with $\mathrm{BMI}<18.5 \mathrm{~kg} / \mathrm{m}^{2}$ presented $\mathrm{CO}$; and all class III obese males were concordantly classified as $\mathrm{CO}$ (Figure 3). In males with BMI ranging from normal to class II obesity, WC in comparison with WHtR underestimated CO: discordance ranged from $2.6 \%$ in class II obese males to $30.3 \%$ in subjects presenting overweight (Figure 3 ). The prevalence of overweight/ obesity was similar to that of the CO estimated by WHtR (Table $2)$, but only $84.3 \%(n=1,117)$ of overweight/obese males presented WHtR $\geq 0.5 .62 .3 \%(n=825)$ overweight/obese males were centrally obese according to WC classification. Total mismatch between BMI and central adiposity measures was higher for WC (23.4\%, e.g. $21.3 \%$ plus $2.1 \%$ ) than for WHtR (15.5\%, e.g. $6.6 \%$ plus $8.9 \%$ ) (Table 3 ).

\section{Females}

Central obesity: The prevalence of $\mathrm{CO}$ according to WC $(41.8 \%)$ was significantly higher in comparison with WHtR $(35.0 \%$, McNemar $\mathrm{p}<0.001)$ (Table 2$)$. WHtR correlated with WC $\left(y=0.006 x+0.007, R^{2}=0.947, p<0.001\right) . W C$ and WHtR concordantly classified central leanness or central obesity in $91.3 \%$ of females, a mismatch was recorded in $8.7 \%$ of subjects (Table 3 ).

In $160 \mathrm{~cm}$ and $161 \mathrm{~cm}$ high females, WC and WHtR classified CO consistently (Figure 1b). $0.9 \%$ of females with $\mathrm{WC}<80 \mathrm{~cm}$ presented $\mathrm{CO}$ according to their WHtR (Table 3). All of them were shorter than $160 \mathrm{~cm}$ (Fig. 1b), thus among these females $4.0 \%$ were classified as $\mathrm{CO}$ by WHtR but were missed using WC. Among females, $7.8 \%$ classified as CO by WC presented WHtR $<0.5$ (Table 3). All of them were taller than $161 \mathrm{~cm}$, thus among taller females (Fig. 1b) the prevalence of this mismatch reached $11.2 \%$.

McNemar's test indicated significant difference in the frequencies of $\mathrm{CO}$ between the methods in all height categories $(\mathrm{p}=0.008$ in $155-159 \mathrm{~cm}$ tall, others: $\mathrm{p}<0.001$ ), except for $160-161 \mathrm{~cm}$ tall females in whom total concordance was observed. In comparison with WHtR, WC overestimated CO in all age-groups but $>70$ years old females, in whom both methods of $\mathrm{CO}$ classification matched (Figure 2). The lowest mismatch (2.2\%) was observed among the 60-69 years old subjects; the highest (10.3\%) in females aged $30-39$ years.

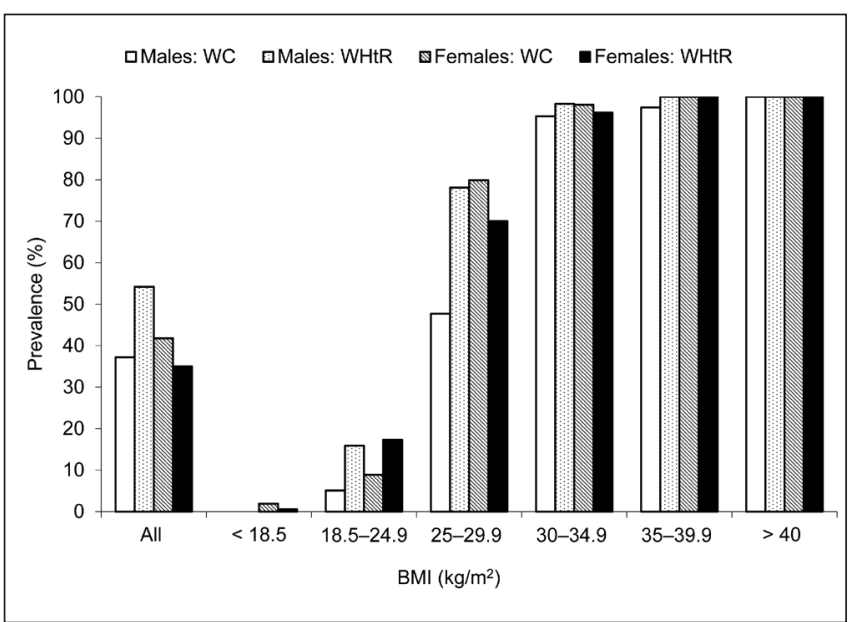

Fig. 3. Prevalence of central obesity estimated by waist circumference (WC) and waist-to-height ratio (WHtR) according to body mass index (BMI) categories in males and females.

Body mass index: In women with $\mathrm{BMI} \leq 34.9 \mathrm{~kg} / \mathrm{m}^{2}$, WC overestimated $\mathrm{CO}$ in comparison with WHtR in $1.3-10.0 \%$ of individuals in different BMI categories (Figure 3). The prevalence of overweight/obesity and CO estimated using WHtR was similar (Table 2). However, only $81.0 \%(n=829)$ of overweight/ obese females presented WHtR $\geq 0.5$; while $87.5 \%(n=895)$ of overweight/obese females presented $\mathrm{CO}$ according to their WC. Among females, discordance between classification according to BMI and WC reached $14.7 \%$ (e.g. $10.2 \%$ plus $4.5 \%$ ), while in case of WHtR it represented $12.5 \%$ (5.7\% plus $6.8 \%$ ) (Table 3 ).

\section{DISCUSSION}

This first study comparing three adiposity measures in apparently healthy Slovak adults shows that the prevalence of overweight, obesity, and $\mathrm{CO}$ is very high. Except for $\mathrm{CO}$ estimated using WC cut-points, the prevalence was higher among males. Discordance between three employed adiposity measures was also more frequent in males than in females. In contrast to our hypothesis, WC vs. WHtR did not show the highest concordance in estimation of $\mathrm{CO}$ in individuals of average height.

\section{General Obesity}

The former Slovak studies reported 36-43\% prevalence of overweight according to BMI cut-points in males and $27-29 \%$ in females; while that of obesity varied between $15 \%$ to $27 \%$ in males and $16 \%$ to $35 \%$ in females (10-12). Our data correspond to the lower ranges indicated for males, but the prevalence of both overweight and obesity was lower in our females. Considering the rising incidence of overweight and obesity worldwide, our data might look paradoxical. However, a relatively low prevalence might be, among others, due to the recruitment: our volunteers might represent subjects being interested in their health status, and thus might stand for a "healthier" part of Slovak population.

While prevalence of obesity in our study exceeded that reported from neighbouring countries for both genders (using BMI), our males presented rather low prevalence of overweight, similar to that reported from Austria. The prevalence of overweight in our 
females appeared even slightly lower than that in neighbouring countries (18). Our males and females presented similar prevalence of class II obesity, while females presented 2-fold higher prevalence of class III obesity in comparison with males. Observed shift towards obesity is particularly alarming since Slovaks present high prevalence of diabetes (9.3\%) (19), and one of the highest cardiovascular mortality rates from among EU-27 countries $(20,21)$.

In contrast to former Slovak studies (10-12), but in accordance with the data from neighbouring countries (18), in our study the prevalence of obesity was higher in males compared to females. This might reflect the general observation that in the last decade BMI and the frequency of obesity increased more steeply in males than in females (22-25). Although in Europe overweight and obesity generally show an inverse socioeconomic gradient, data from 2002 suggest that this relationship holds true only for Slovak women (18). Educational attainment was not tracked in our studies, but we estimate that majority of volunteering subjects received secondary or higher education. This might have influenced the observed higher prevalence of obesity among males.

\section{Central Obesity}

Single former Slovak study reporting prevalence of CO according to IDF criteria estimated that $47 \%$ of males and $54 \%$ of females were centrally obese (10). In our study, the prevalence was lower. However, in both studies the prevalence was higher among females compared to males. On the other hand, WHtR used to classify $\mathrm{CO}$ in our study yielded, strikingly, higher prevalence of CO in males than in females. We asked whether this discrepancy might stem from the fact that the average anthropometric characteristics, particularly the height, of our participants deviated from an average reported for Slovak adults. According to the EHIS study, the average height of adult Slovak male was 177.6 $\mathrm{cm}$, average weight was $82.8 \mathrm{~kg}$, and that of BMI reached 26.2 $\mathrm{kg} / \mathrm{m}^{2}$ (12). Grasgruber et al. (26) reported the average height of $179.3 \mathrm{~cm}$. An average adult female height was $165.2 \mathrm{~cm}$, average weight $67.9 \mathrm{~kg}$, and BMI $25.0 \mathrm{~kg} / \mathrm{m}^{2}$ (12). According to data from the 7th Nationwide Survey (22), average heights of 18-years old males and females correspond to those reported in the EHIS study (12). Thus, the anthropometric characteristics of our male and female cohorts acceptably reflect those of White Caucasian Slovak adults.

In males, both methods concordantly classified CO in subjects slightly taller than average plus 1 SD (e.g. in those $188-9 \mathrm{~cm}$ tall). In shorter males ( $<188 \mathrm{~cm}$ tall), accounting for $90 \%$ in our cohort, WC underestimated CO if compared with WHtR; while in those taller than $189 \mathrm{~cm}$ (representing $6 \%$ of our males), WC overestimated CO in comparison with WHtR. This mismatch stemmed from the fact that in our males WHtR of 0.5 corresponded to WC of $89 \mathrm{~cm}$ (and WC of $94 \mathrm{~cm}$ to WHtR of 0.52). Among females, concordance was reached in those shorter from the average by $1 \mathrm{SD}$ of height (e.g. those $160-1 \mathrm{~cm}$ tall). Thus, in females shorter than $160 \mathrm{~cm}$ (accounting for $16.5 \%$ of all females) WC in comparison with WHtR underestimated $\mathrm{CO}$, while in those taller than $161 \mathrm{~cm}$ (73.0\% of the cohort) WC overestimated CO if compared with the WHtR classification. In contrast with males, in females estimation of $\mathrm{CO}$ using WHtR underclassified $\mathrm{CO}$ in comparison with WC. This stems from the fact that in Slovak females WHtR of 0.5 corresponds to WC of $83 \mathrm{~cm}$, and WC of $80 \mathrm{~cm}$ corresponded to WHtR of 0.49 . Mismatch between the methods was 2-fold higher in males in comparison with females. In both genders discordance was more frequent in young and middle aged subjects, reflecting a well-known age-dependent rise in frequency of $\mathrm{CO}(9,10)$.

BMI vs. WHtR misclassified $15.5 \%$ males and $12.5 \%$ females. These percentages are similar to those reported previously (8). However, while in this study approximately $75 \%$ from the mismatched subjects where those at risk by WHtR but missed by BMI screening, in our cohorts the proportion of those at risk by BMI but not at risk by WHtR was higher. Total mismatch between BMI and WC was the highest among the compared methods in both genders, pointing to overestimation of adiposity by BMI vs. $\mathrm{WC}$ in males and underestimation in females.

The main strengths of our study are its large size and the use of objective measures of weight, height and waist circumference. Elderly participants were not institutionalized. One possible limitation is that the gender, age and educational level structure do not closely resemble the socio-demographic distribution of the Slovak population. Our probands were not completely independent, close relatives and family members might have participated. We did not collect data on determinants of obesity, such as socioeconomic status, dietary habits, alcohol intake, or physical activity. Anthropometric data were collected according to the same protocol, scales from one manufacturer and portable stadiometers of the same provenance were used. All staff members participating in anthropometric data collection where either employees or students of the Slovak Medical University, Faculty of Medicine of Comenius University or the Public Health Authority of the Slovak Republic. Participating students were rigorously trained to perform data collection, and during measurements performance they were supervised by employees of the mentioned institutions. However, we cannot exclude bias in data collection.

\section{CONCLUSION}

The prevalence of overweight/obesity and CO among apparently healthy Slovak adults is very high and should be compellingly tackled by appropriate policies of the institutions in charge. We confirmed the accepted assumption that in comparison with WHtR, WC, a method recommended by numerous professional organizations, overestimates central obesity in taller subjects. However, in our cohort this overestimation was observed only in males presenting height by about one standard deviation above the average; while in females it was in those who were shorter than an average minus one standard deviation. Further studies addressing the discordance of $\mathrm{CO}$ measures are required to determine whether our results are consistent across geographical regions and ethnic groups. As WHtR seems to be a better predictor for estimation of future cardiometabolic risk, data from different populations could provide basis for decision-making policies of the institutions in charge with regard to estimation of the central obesity associated risk evaluation.

\section{Conflict of Interests}

None declared 


\section{Funding}

This study was partially supported by a grant from the Slovak Research and Development Agency No.: 0447-12 (KS); and by the framework of realization of the project "Centre of excellence of environmental health", ITMS No.26240120033, based on the supporting Operational Research and Development Programme financed from the European Regional Development Fund. Studies included into this secondary analysis were supported by grants from the Ministry of Health of the Slovak Republic No.: 2005/42-SZU-20 (AL), 2005/27-SZU-05 (MG), 2006/07-SZU-02 $(\mathrm{KV})$; and Bratislava Self-governing Region. The funders had no role in study design, data analysis, decision to publish, or preparation of the manuscript.

\section{REFERENCES}

1. Lee CM, Huxley RR, Wildman RP, Woodward M. Indices of abdominal obesity are better discriminators of cardiovascular risk factors than BMI: a meta-analysis. J Clin Epidemiol. 2008;61(7):646-53.

2. Ashwell M, Gunn P, Gibson S. Waist-to-height ratio is a better screening tool than waist circumference and BMI for adult cardiometabolic risk factors: systematic review and meta-analysis. Obes Rev. 2012;13(3):27586.

3. Browning LM, Hsieh SD, Ashwell M. A systematic review of waist-toheight ratio as a screening tool for the prediction of cardiovascular disease and diabetes: 0.5 could be a suitable global boundary value. Nutr Res Rev. 2010;23(2):247-69.

4. Alberti KG, Eckel RH, Grundy SM, Zimmet PZ, Cleeman JI, Donato KA, et al. Harmonizing the metabolic syndrome: a joint interim statement of the International Diabetes Federation Task Force on Epidemiology and Prevention; National Heart, Lung, and Blood Institute; American Heart Association; World Heart Federation; International Atherosclerosis Society; and International Association for the Study of Obesity. Circulation. 2009;120(16):1640-5.

5. Expert Panel on Detection, Evaluation, and Treatment of High Blood Cholesterol in Adults. Executive summary of the third report of the National Cholesterol Education Program (NCEP) Expert Panel on Detection, Evaluation, And Treatment of High Blood Cholesterol in Adults (Adult Treatment Panel III). JAMA. 2001 May 16;285(19):2486-97.

6. Hsieh SD, Yoshinaga $\mathrm{H}$. Waist/height ratio as a simple and useful predictor of coronary heart disease risk factors in women. Intern Med. 1995;34(12):1147-52.

7. Ashwell M, Lejeune S, McPherson K. Ratio of waist circumference to height may be better indicator of need for weight management. BMJ. 1996;312(7027):377. doi: https://doi.org/10.1136/bmj.312.7027.377.

8. Ashwell M, Gibson S. A proposal for a primary screening tool: 'Keep your waist circumference to less than half your height'. BMC Med. 2014;12:207. doi: 10.1186/s12916-014-0207-1.

9. Gutiérrez-Fisac JL, Guallar-Castillón P, León-Muñoz LM, Graciani A, Banegas JR, Rodríguez-Artalejo F. Prevalence of general and abdominal obesity in the adult population of Spain, 2008-2010: the ENRICA study. Obes Rev. 2012;13(4):388-92.

10. Mokáň M, Galajda P, Prídavková D, Tomášková V, Šutarík L', Kručinska L', et al. Prevalence of diabetes mellitus and metabolic syndrome in Slovakia. Diabetes Res Clin Pract. 2008;81(2):238-42.
11. Dukát A, Lietava J, Krahulec B, Caprnda M, Vacula I, Sirotiaková J, et al. The prevalence of abdominal obesity in Slovakia. The IDEA Slovakia study. Vnitr Lek. 2007;53(4):326-30. (In Slovak.)

12. Gerhardtová A. EHIS 2009 - European Health Interview Survey 2009. Bratislava: Statistical Office of the Slovak Republic; 2011. (In Slovak.)

13. Volkovova K, Gasparovic J, Raslova K, Staruchova M, Dusinska M. Individual health risk factors and frequency of obesity in Slovakia. J Environ Orig Health Dis. 2009;1 Suppl 1:S115.

14. Vičanová M, Pinter I, Líšková A. Monitoring of radiation burden of aircraft crew from exposure to cosmic radiation. In: Jurkovičová J, Štefániková Z, editors. Living conditions and health. Bratislava: Public Health Authority of the Slovak Republic; 2009. p. 242-7. (In Slovak.)

15. Bacharova L, Krivosikova Z, Wsolova L, Gajdos M. Alterations in the QRS complex in the offspring of patients with metabolic syndrome and diabetes mellitus: early evidence of cardiovascular pathology. J Electrocardiol. 2012;45(3):244-51.

16. Kollárová R, Gerová Z, Potičný V, Šebeková K. Prevalence of overweight and obesity in Bratislava highschool students - preliminary results of study „Respect for Health“. Cesk-Slov Pediatr. 2013;68(4):211-8. (In Slovak.)

17. Alberti KG, Zimmet P, Shaw J. Metabolic syndrome - a new world-wide definition. A Consensus Statement from the International Diabetes Federation. Diabet Med. 2006 May;23(5):469-80.

18. Roskam AJR, Kunst AE, Van Oyen H, Demarest S, Klumbiene J, Regidor E, et al. Comparative appraisal of educational inequalities in overweight and obesity among adults in 19 European countries. Int J Epidemiol. 2010;39(2):392-404

19. International Diabetes Federation [Internet]. Brussels: IDF [cited 2018 May 4]. Available from: https://www.idf.org/e-library/consensusstatements/60-idfconsensus-worldwide-definitionof-the-metabolicsyndrome.html.

20. World Health Organization. The European health report 2012: charting the way to well-being [Internet]. Copenhagen: WHO; 2013 [cited 2015 May 13]. Available from: http://www.euro.who.int/_data/assets/ pdf_file/0004/197113/EHR2012-Eng.pdf.

21. Nichols M, Townsend N, Scarborough P, Rayner M. Cardiovascular disease in Europe 2014: epidemiological update. Eur Heart J. 2014;35(42):2950-9.

22. Physical development of children and youth in Slovakia. Results from 7 th nationwide survey in 2011 [Internet]. Bratislava: Public Health Authority of the Slovak Republic; 2014 [cited 2015 May 13]. Available from: http:// www.uvzsr.sk/docs/info/hdm/Antropometria.pdf. (In Slovak.)

23. Salcedo V, Gutiérrez-Fisac JL, Guallar-Castillón P, Rodríguez-Artalejo F. Trends in overweight and misperceived overweight in Spain from 1987 to 2007. Int J Obes (Lond). 2010;34(12):1759-65.

24. Flegal KM, Carroll MD, Ogden CL, Curtin LR. Prevalence and trends in obesity among US adults, 1999-2008. JAMA. 2010;303(3):235-41.

25. Lahti-Koski M, Seppänen-Nuijten E, Männistö S, Härkänen T, Rissanen $\mathrm{H}$, Knekt $\mathrm{P}$, et al. Twenty-year changes in the prevalence of obesity among Finnish adults. Obes Rev. 2010;11(3):171-6.

26. Grasgruber P, Cacek J, Kalina T, Sebera M. The role of nutrition and genetics as key determinants of the positive height trend. Econ Hum Biol. 2014;15:81-100. 